\title{
The Phoenix with Elephant Trunk: the First Study of Mythical Creature on the House Ridge of Dai Nationality in Jinghong
}

\author{
Chunji Zhang \\ Sichuan Fine Arts Institute \\ Chongqing, China
}

\begin{abstract}
This paper adopts research method of anthropology of art and conducts field study on "mythical creature on the house ridge" of Dai nationality in Jinghong. Through introduction to the most representative "phoenix with elephant trunk" and other mythical creature pictures on the house ridge of Buddhist temple of Daile(Water Dai) in Jinghong, this paper summarizes usage of "mythical creature on the house ridge" in Buddhist temple of Dai nationality and current situation of handmade "mythical creature on the house ridge" as an earthenware in Dai nationality.
\end{abstract}

Keywords-Dai nationality in Jinghong; Buddhist temple architecture; Mythical creature on the house ridge; Handmade earthenware

\section{DAI NATIONALITY IN JINGHONG}

Jinghong is located in Xishuangbanna, which is on the south of Hengduan Mountains, on northern edge of tropical zone, and on the end of Wuliangshan and Nushan Mountains. It has the good reputation of "Animal kingdom" and "Plant kingdom". There are 13 branches of long-dwelling people: Dai, Lahu, Hani, Brown, Jino, Han and so on. Dai nationality is descendant of Baiyue nationality and is integration of Baiyue and native nationalities. Dai nationality calls itself "Dai" or "Tai". In Han dynasty, it is called "Dianyue" or "Dan". In Tang dynasty, it is called "Gold Tooth, Black Tooth, Silver Tooth, Mangman and Pandura". In Song dynasty, it is called "Gold Tooth" and "Pandura". In Yuan and Ming dynasties, it is called "White Yi". In Qing dynasty, it is called "Baiyi". Dai nationality in Jinghong of Xishuangbanna is mainly divided into three branches: Daile(Water Dai), also called "Water Baiyi"; Daine(Handai), also called "Hanbaiyi"; Daiya(Huayao Dai), also called "Huabai Yi". Daile(Water Dai) in Jinghong has the largest population, prosperous Buddhism and universally used ceramic products of Buddhist temple. The mythical creature on the house ridge of Buddhist temple architecture is a kind of cultural representative to some degree.

Project: The Phoenix with Elephant Trunk: The First Study of Mythical Creature on the House Ridge of Dai Nationality in Jinghong is one of the papers of Chongqing social science planning project "Southwest Minority Mythical Creature on the House Ridge Research"(Person in charge: Zhang Chunji, Project No.: 2015PY21) series.

\section{Buddhist TEMPLE ARCHITECTURE AND MYTHICAL CREATURE ON THE House RidGE OF DAi NATIONALITY IN JINGHONG}

\section{A. Buddhist Temple Architecture of Dai Nationality}

Buddhist temple of Dai nationality is called "vat(wa)" in Dai language in Jinghong. It may originate from the meaning of "vnao(park)" in Pali. It is called "Burmese temple" in Chinese and called "Leifang" in Dai nationality area in Dehong, which means school or temple. Almost every village in Dai nationality area in Jinghong has Buddhist temples. Buddhist temples and pagodas are usually the highest buildings in Dai village. There should be large public space and tall trees surround Buddhist temples, which should also have low walls, gable and hip roof with double eaves, memorial gateway like doors, lead gallery which is not so long, and beautiful pagoda inside the monastery. Buddhist temples of Dai nationality in Jinghong usually consist of terakado, Buddhist hall, scripture hall, shag, antrum tympanicum and so on.

Terakado of Buddhist temple of Dai nationality usually faces east. The temple has memorial gateway like gable and hip roof with double eaves. The door of Buddhist temple of Dai nationality usually has no door plank. Memorial gateway house ridge is decorated with ceramic auspicious animals of mythical creature. There is fresco on wooden wall beneath the eaves. There are dragon shaped mythical creatures on both sides of the gate as guards. Lead gallery is the transition space between gate and great hall, and believers can "circumcise and conduct sedimentation-filtration" here to prepare for devoutly paying respect for Buddha psychologically. Buddhist hall is called "Wei han" in Dai language. There is only one Buddha Shakyamuni sitting in the west and facing the east in the great hall. Other small figures of Buddha worshiped by believers have to be placed in front of and on the left and right side of Xumizuo. "Scripture hall" (Ordination hall) is called "Bu su" in Dai language, where Buddhas chant sutras, discuss official business, confess and promote Buddhas. The "octagonal pavilion" of Jingzhen village in Mengzhe town of Menghai country is a model of architectural art of scripture hall. The eight angles represent 8 eminent monks around Buddha Shakyamuni. The four gates of octagonal pavilion respectively 
in the east, west, south and north represent spreading of Buddha dharma in all directions. In modeling, the prominent important characteristic of Buddhist temples of Dai nationality in Jinghong is gable and hip roof with double eaves. The whole roof is in curvilinear shape with raised middle part and gradual decrease in height with division of three-one-five section on both sides, forming richly changeable outline and making Buddhist temples magnificent and luxury.

\section{B. Mythical Creature on the House Ridge with Phoenix with Elephant Trunk as Its Representative}

Mythical creatures used in Buddhist temples of Dai nationality in Jinghong mainly are: (1) Phoenix with elephant trunk, called "A chi li hong gong hong (Ha sa li li ling)". For instance, lark is a kind of mythical bird guarding noble people. It is regarded as ride of prince and princess in folk and it is placed on coffin in folk to meet and guide the soul going up to heaven; (2) A kind of phoenix called "o" in Dai language is a tolerant and honest guardian angel. It can be wherever its own master is and its modeling is dragon head and phoenix body; (3) A kind of mythical creature managing the water with bird head which is called "Ho" in Dai language. It can dive into the water and go into the heaven and it is more powerful than dragon; (4) "Gei na li" in Dai language belongs to peacock princess family and it has human body and phoenix tail; (5) "A nu meng" in Dai language is a military officer and a guardian angel, which is usually placed in front of temple gate with human head and monkey tail; (6) "Meng" in Dai language is a kind of mythical creature with a big mouth. It is gluttonous and cute and is usually placed at the temple gate; (7) Phoenix is called "hong" in Dai language and it is the most beautiful bird; (8) Auspicious clouds floating on house ridge are called "Mi da" in Dai language; (9) Auspicious clouds floating on the upper end of vertical ridge are called "Mi lai" in Dai language; (10 Lion is called "Xing" in Dai language; D Kylin is called "Li za xi" in Dai language; $\mathbb{1}$ Elephant is called "zhang" in Dai language; $\mathbb{1} 2$ Horse is called "mang" in Dai language; $\mathbb{B}$ Dragon is called "La" in Dai language; (4) Dragon shaped mythical creature is called "Laga" in Dai language. The most necessary mythical creature for residents of Dai nationality in Jinghong is peacock, called "long rong" in Dai language. It represents wealth and richness. However, it does not mean that every family can afford to raise it. The family firstly needs to check horoscope with the Buddha. Then suitable family can use it.

Phoenix with elephant trunk and "o" are the most frequently-used and most representative mythical creatures on house ride in Buddhist temples of Dai nationality in Jinghong "Fig. 1". Buddhist temple's ridge modeling of Dai nationality in Jinghong is different from double eaves gable and hip roof as an entire body of Han nationality. But they both have genes influencing each other. Just like decorations of earthen celestial being and birds and animals on house ridge and pagoda top and pagoda decorations in center of ridge, mythical creature decorations on house ridge are not only for the seek of good appearance, more importantly, they represent specific religious meaning and system. Tower-like metal accessories in the center of main temple hall's house ridge is called "Sapa" or
"Ta sa" in Dai language, representing "heaven"; Phoenixes on both ends define the range of "heaven"; Flamboyant "auspicious clouds" on ridge of both sides are called "Mi da" in Dai language; Tile ornaments with leaf roll shaped pattern on vertical ridge are called "Mi lai" in Dai language, symbolizing clouds in the heaven. Head end of the folding of the ridge is usually "o" or phoenix with elephant trunk. There are 6 ceramic lotus fruits on ridge, which are installed around tower-like "Ta sa", with 3 on each side. Hollow wooden hanging fish is installed under pediment of gable and hip roof and liquid gold picture is painted on wooden partition under pediment roof. These gorgeous decorations entering the Buddhist temple symbolize entering the blissful Buddhist country among clouds in the heaven. Ceramic mythical creature ornament and engraving skip printing liquid gold picture with red bottom and gold line on house ridge give people full fantasy to surpass the reality. In terms of expression, ceramic mythical creatures on house ridge are mainly circular engravure or double-sided relief. Some of them are imitation of modeling and pattern of manifestation of scissor-cut of Dai nationality. Mythical creatures on the ridge and liquid gold pictures inside and outside the wall of buddha-hall and on pillar and beam of main temple hall constitute magnificence of the whole Buddhist temple, forming striking contrast with simple and plain local family bamboo house of Dai nationality.

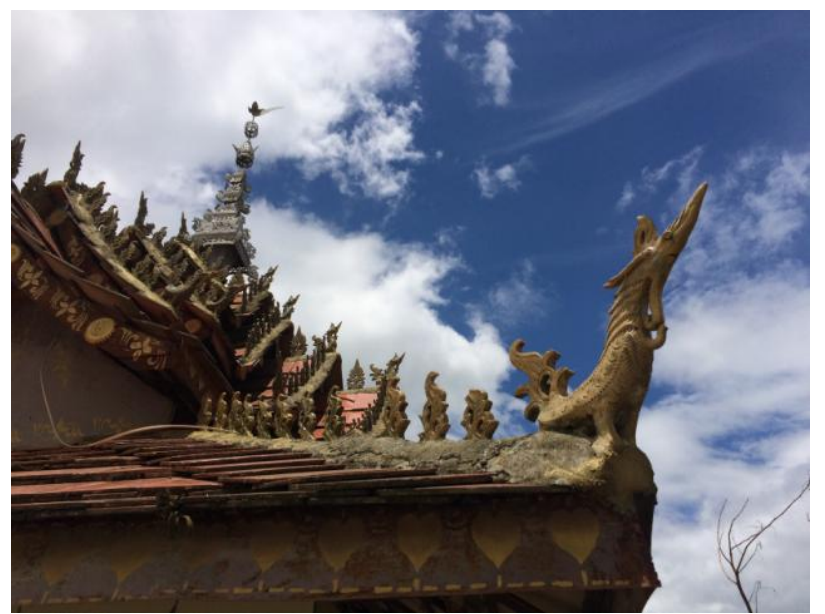

Fig. 1. The mythical creature "phoenix with elephant trunk" on house ridge of "octagonal pavilion" Buddhist temple in Jingzhen Village, Mengzhe Town, Menghai County

\section{PRODUCTION STATUS OF EARTHENWARE AND} HANDMADE EARTHENWARE OF MYTHICAL CREATURE ON THE RIDGE OF DAI NATIONALITY IN JINGHONG

\section{A. Production Mode of Earthenware of Dai Nationality}

Seeing from document of Baiyi Zhuan of Hongwu Period in Ming dynasty, there is recordation of production mode of earthenware of Dai nationality: "The utensil is extremely ugly. There is no bucket, muji or wooden basin. The only things to use are earthenware and metal tools. Advocated government decree is to use gold, silver and glass utensils. The following is also made of gold and silver." At present, potting technique of various villages of Dai nationality keeps activate states of different types. Technology of making mould includes: No 
wheel and have a wheel, there is toe-slowly-moving wheel and hand-moving wheel in terms of blank forming mode, there is flat ground pottery making, simple closed earth kiln and modern closed kiln in terms of pottery making technology. However, many utensils keep traditional styles in shape and structure and line-adorning. Modern work flow of pottery making of Dai nationality is almost the same as traditional type, which is mainly divided as: (1) soil unloading; (2) sand unloading; (3) spring soil; (4) filtrating clod; (5) mixing sand and soil; (6) blank forming; (7) abortion to make a shape; (8) beating pattern; (9) drying; (10) preparations before burning; (10) pottery output, 12 working procedures in total.

According to recording in Le History of Dai nationality, in $1180 \mathrm{AD}$ (The 542 year of Dai lunar calendar), Bazhen, leader of Dai nationality, unites more than 30 Meng with modern Xishuangbanna in Jinghong as the center and establishes local authority of "Jinglong Gold Temple Country" which is under management of Kingdom of Dali in Song dynasty. In Yuan dynasty, Xishuangbanna is incorporated into Tusi management system and is set as military and civilian feudal official of Cheli. In 1570 of Ming and Qing dynasties, Dao Yingxun is Xuan wei shi of Cheli. He divides the jurisdiction into 12 administrative units: Xishuangbanna, in Dai language: Xishuang means 12 and Banna means 12 Meng. After establishment of Jinglong Gold Temple Country, Xuan wei si is about $6 \mathrm{~km}$ from current Jinghong. The most superior governor of Dai nationality lives in Xuan wei si, around which there is Manle, Mankongzhan, Mangangjing, Manpacha, Huixiu, Manluandong and Mansu, 6 villages in total. They provide different commodity services for the highest Tusi of Day nationality according to division of labor. "Manlezhai" is the village exclusively making life earthenware and Buddhist temple construction earthenware for imperial court among the six villages.

According to recollection of potting inheritor of Mangezhai in Jinghong city, namely Yan Handian, there are only 27 households in Manle village. Basically, all of them make earthenware. At that time, earthenware utensils made by them include: water pot, dish plate and eating bowl as articles of daily use; water-dripping kettle, the Buddha and begging bowl with advocated practicality as religious oblation; and mythical creature on house ridge and tile ornaments for Buddhist temple architecture, more than 20 varieties in total.

\section{B. Current Status of Earthenware Inheritor of Dai Nationality}

With strong impact of foreign industrial products, metal and plastic products come to Dai people's life in Jinghong in great quantity. Usage of earthenware products gradually and constantly disappears from Dai people's view. People mastering handmade production method of products used on Buddhist temple architecture in folk Dai nationality in Xishuangbanna and slow wheel pottery making method used in production of articles of daily use are becoming fewer and fewer. Most inheritors give up their skills and rush for make a fortune one after another in market economy of economic benefit maximization. Few villagers stick to skills due to different reasons. Villagers and inheritors still making earthenware products are: Yu Nan'en, Yu La, Yu Jiao, Yu Wen, Yu Nanhan, Yu Tan and so on, 9 artists and inheritors of Man fei long village in Menglong town, Jinghong city; Inheritors of Mange village in Jinghong city are Yan Handian and Yu Zhangfeng; Yu Meng, inheritor of Mandou village in Jinghong city; Yu Nannan, Yu Ernuo, Yu Yingnan and Yu Lanan, 4 inheritors in Manlang village of Mengzhe town, Menghai county; Yu Xianglun, inheritor of Mengjinglai village, Daluo town, Menghai county; Yan Guanghan, Yan Wenjiao and Yan Shuo, inheritors of Jingzhen village, Mengzhe town, Menghai county.

After moving to Mange village from Manle village, Yan Handian family, including Yu Yan grandma, Su Taoweng grandpa, mother-Yu Zuhan and father-Yan $\mathrm{Pa}$, restore handmade earthenware. In Yan Handian's family, men make mythical creatures on the house ridge and tile ornaments used in Buddhist temple architectures and women make low wheel earthenware articles of daily use. Yu Zhangfeng is the current inheritor of Yan Handian's family. On the basis of retaining traditional earthenware modeling, production mode gets constant innovated. Right now, there are more than 100 new product varieties.

\section{Handmade Earthenware and Firing of Mythical Creatures on the House Ridge}

Earthenware articles of Buddhist temples of Dai nationality in Jinghong can be reduced to two types: architecture articles and sacrifice articles. Mythical creatures on the house ridge belong to Buddhist temple articles and architecture articles. Basically, they are all made by male. Up to now, artists making mythical creatures on the house ridge in Xishuangbanna get very few. According to preliminary investigation, there are only 5 people sticking to manufacturing of ceramic mythical creatures on the house ridge of Buddhist temple, namely Yan Handian and Yu Zhangfeng in Mange village of Jinghong city, and Yan Guanghan, Yan Wenjiao and Yan Shuo in Jingzhen village, Mengzhe town, Menghai county "Fig. 2" and "Fig. 3".

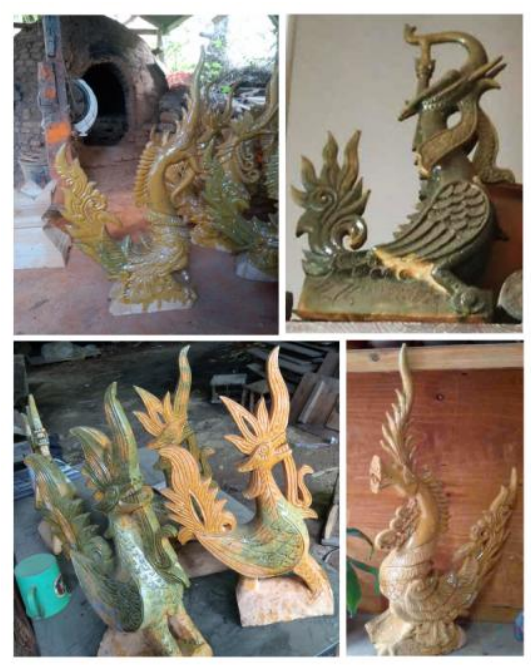

Fig. 2. Phoenix with Elephant Trunk and $O$-- Works of Yan Handian and Yu Zhangfeng(On upper left, upper right and lower right) and works of Yan Guanghan, Yan Wenjiao and Yan Shuo(On lower left) 


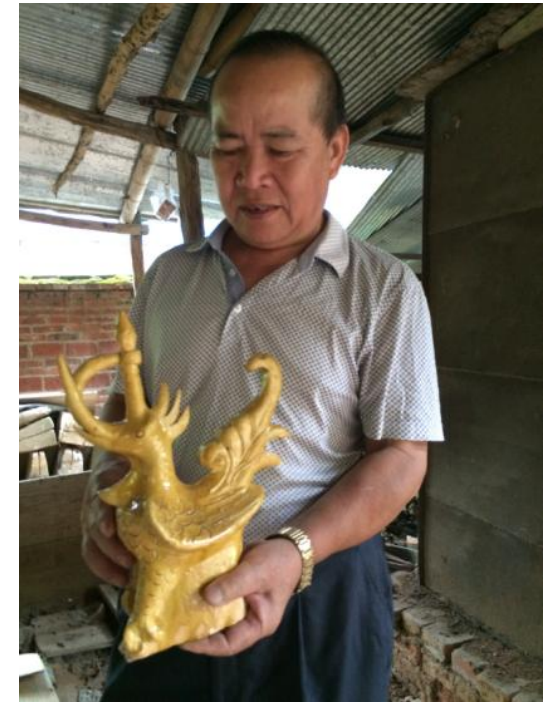

Fig. 3. Yan Handian and his works Phoenix with Elephant Trunk

When making mythical creatures on the house ridge, they totally rely on memory and feeling and constantly modify pug used for manufacturing on the slow wheel. The technology to make mythical creatures is quite difficult and complex and there are many tools to use. Essential tools made with local materials are: wooden pat, bamboo knife, graver, fruit knife, paper knife and carving knife. Characteristic tools are: arcshaped "wood scraping", wooden "curved rod", "Qing cylinder" made of a bamboo section, "rotating bar" made of a bamboo stick or wood stick, and leguminous plant "elephant bean" to polish the surface of earthenware to make it smooth. When making mythical creatures on the house ridge, if it is a singular product, they make the base according to their conception from shape forming. They make while pinching and use tools of engraving, carving, digging, filling and wiping and techniques to make mythical creatures on the house ridge. For mass production, they will firstly make rudiments to fix the size, and then gradually process till completion. After greenware of mythical creatures on the house ridge is completed, firstly place it in a ventilated place to dry in the shade, then place it under the sunshine. After the greenware is completely dry, do glazing on it. There are 2 traditional methods for glazing: mud glaze and lead glaze. Manufacture method of mud glaze is: use relative pure clay to dissolve, add straw ash, filtrate impurities to make it in thick juice state and add water to make it butyrous as long as it can cover the original color of greenware. Normal manufacture method of glaze is: add straw ash after lead dissolves and stir evenly. When glazing, smear dissolved lead liquid on greenware of mythical creature on the house ridge uniformly. When glaze material gets cold, it can be placed in the kiln for firing. The kiln for firing mythical creatures is in round shape with a diameter of about 1.5 meters and a height of 3 meters and it is made of red bricks on the flat ground. When four peripheries are well built, two openings of $50 \mathrm{~cm}$ wide and $70 \mathrm{~cm}$ high need to be built on the side without soil for adding fuel. Apart from lighting-up tuyere, a step of about $40 \mathrm{~cm}$ high needs to be built where around 1/3 of kiln body from bottom for placing greenware for firing. Use disposable bricks to seal the top and use straw to cover and paste mud. Plastic tunnel is usually built overhead for sheltering to ensure normal firing of earthenware in rainy days.

\section{CONCLUSION}

Dai nationality is a nation basically whose entire people believe in Theravada Buddhism. After introduction and acceptance of Theravada Buddhism in Jinghong, in mutual dissolving of central plain culture and Theravada Buddhism culture, Dai nationality culture is enriched, forming specific nation culture and Buddhist temple architecture features of Dai nationality in Jinghong.

Spreading of unique mythical creature on the house ridge is a nation's belief and memory of culture and religion. Dai nationality in Jinghong uses "phoenix with elephant trunk", "Hu", “O”, "Meng", "Anumeng", "Laga", "kylin", "lion", "elephant", "mythical horse", "peacock" and other mythical creatures to maintain Buddhist temple's dignity and system. Use compound image-making method to integrate people's wishes of various auspiciousness, praying and stewardship on mythical creatures into a whole. Phoenix with elephant trunk, kylin with elephant trunk, dragon head and phoenix body, elephant with long peck, human body and phoenix tail, human head and monkey tail and auspicious clouds on house back are full of mysterious color and these mythical creatures jointly constitute religious spirit and significance of Buddhist temple of Dai nationality in Jinghong. More importantly, they spread this kind of culture to every Dai people in Jinghong.

\section{REFERENCES}

[1] Introduction to Yunnan Ethical Fine Arts, Li Jinghuan and Tang Haitao. Kunming: Yunnan Fine Arts Press, 2005.12

[2] Material Culture in Yunnan - Life Technology Volume, by Tang Li. Kunming: Yunnan Education Press, 2005.5

[3] Slow Wheel Ceramics of Dai Nationality, by Duan Qiru. Kunming: Yunnan Nationalities Publishing House, 2014.8

[4] Mandou Dai Nationality Slow Wheel System, by Zhang Haichao. Kunming: Yunnan People's Publishing House, 2009.7 